\title{
Geophysical Feasibility Study to Identify Signs of Chimney Drain/Drainage Blanket Clogging in Canyon Dam Canyon Lake, Comal County, Texas
}

By Janet Simms and Katie Martin

PURPOSE: To determine the feasibility of using geophysical methods for detecting/identifying areas that may be clogged within the chimney drain and/or drainage blanket.

INTRODUCTION: A geophysical feasibility study was conducted 18-22 AUG 2015 at Canyon Dam, located in Canyon Lake, Comal County, Texas, by Dr. Janet Simms and Ms. Katie Martin of the Geotechnical Engineering and Geosciences Branch (GEGB), Geotechnical and Structures Laboratory (GSL), U.S. Army Engineer Research and Development Center (ERDC), Vicksburg, Mississippi. The survey was conducted at the request of the Geotechnical Branch, U.S. Army Corps of Engineers (USACE), Fort Worth District (SWF). The Fort Worth District point of contact was Ms. Sarwenaj Ashraf. The investigators were assisted by Canyon Lake office personnel Mr. Marcus Schimank, Canyon Lake Manager, and Mr. John Jacobs, CE Technician. Mr. Lucas Walshire, ERDC, provided the modeling results discussed below.

Canyon Dam is located at river mile 303.0 on the Guadalupe River about 12 miles (19 km) northwest of New Braunfels, Texas (Figure 1). It is a rolled earth-fill embankment with a core comprised of a well-compacted, high-plasticity material $(\mathrm{CH})$ and an embankment shell constructed of well-compacted CL material. The crest length measures 4,410 ft (1,344 $\mathrm{m})$ and has a height of $224 \mathrm{ft}(68 \mathrm{~m})$ at elevation $972.87 \mathrm{ft}(296.5 \mathrm{~m})$. Construction of the dam was completed in 1964. The chimney drain extends vertically from the drainage blanket to approximately $31 \mathrm{ft}$ $(9.5 \mathrm{~m})$ below the crest (to elevation $943.3 \mathrm{ft} / 287.5 \mathrm{~m}$ ) along the length of the dam. The chimney drain is $10 \mathrm{ft}(3 \mathrm{~m})$ wide, and its center is located $25 \mathrm{ft}(7.6 \mathrm{~m})$ east of the crest centerline. The drainage blanket is $5 \mathrm{ft}(1.5 \mathrm{~m})$ thick with its bottom located at elevation $780.3 \mathrm{ft}(237.8 \mathrm{~m})$. The filter material consists of processed stone obtained from nearby limestone quarries.

Because the chimney drain and drainage blanket cover a large spatial extent, it was decided that clogging in either would likely result in a rise of the conservation pool phreatic surface. A simplistic modeling exercise was performed to estimate the change in phreatic surface from unclogged, conservation pool conditions $(909.3 \mathrm{ft} / 277.2 \mathrm{~m})$ to partially and fully clogged, conservation pool conditions. All analyses were run at steady state, and material properties and models are the same as those used during the Semi-Quantitative Risk Assessment (SQRA, July 2014) at station $72+50$. Permeability values for partially and fully clogged conditions were assumed to be two and three, respectively, orders of magnitude lower than the unclogged permeability value. 


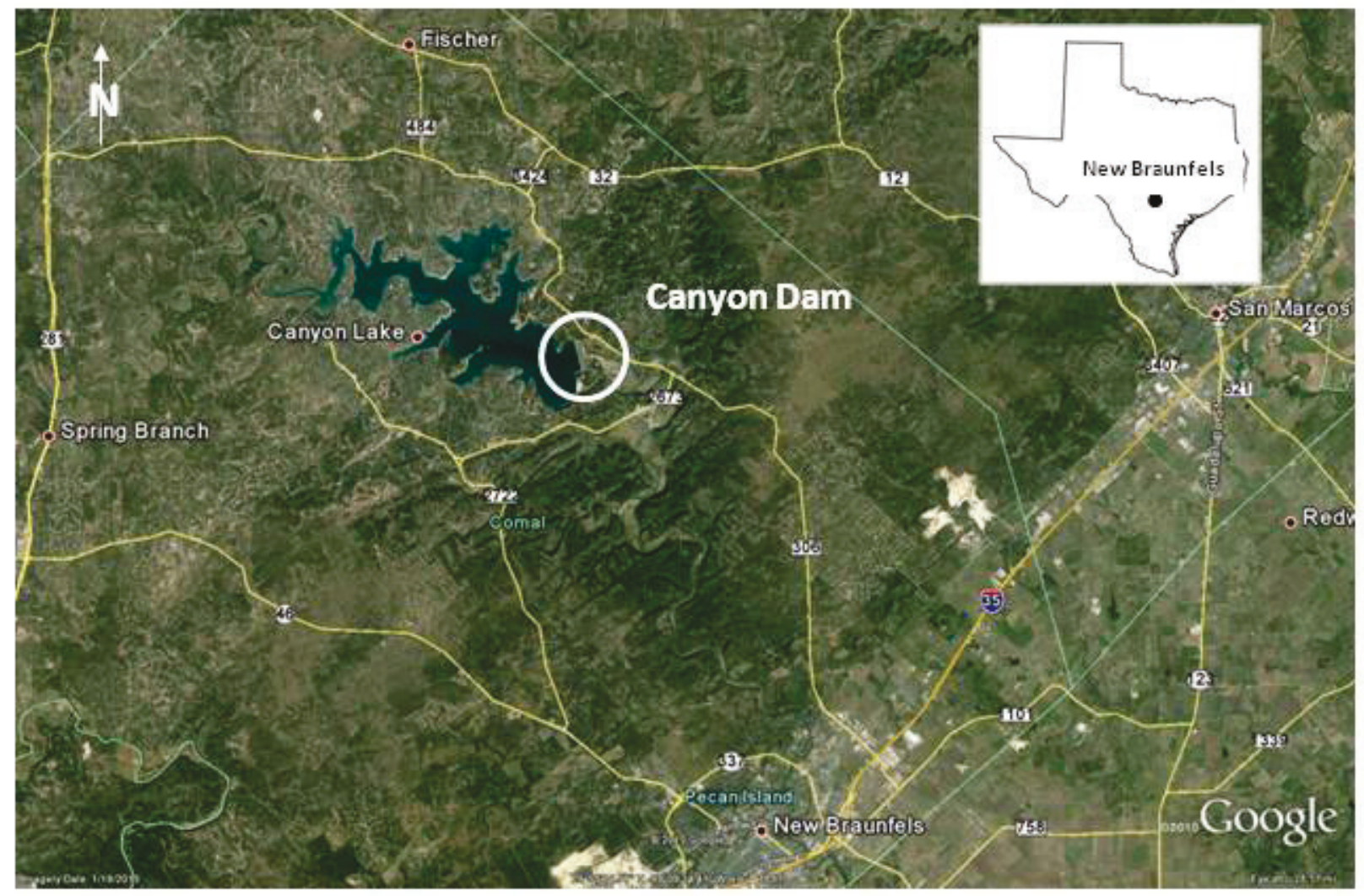

Figure 1. Location of Canyon Dam in Canyon Lake, Comal County, Texas.

The height of the chimney drain $(\sim 158 \mathrm{ft} / 48 \mathrm{~m})$ and variable depth to the drainage blanket, depending on location along the downstream embankment, requires a geophysical technique that can provide sufficient depth of investigation without sacrificing resolution. Based on these considerations, it was decided that electrical resistivity (ER) sounding would be the preferable method to detect the water level within the embankment. Prior to arriving on site, it was thought that the drainage blanket extended from the ground surface to $5-\mathrm{ft}(1.5-\mathrm{m})$ depth at the toe of the dam. Based on this knowledge, ground penetrating radar (GPR) and two electromagnetic induction (EMI) sensors were selected also to better characterize the drainage blanket. However, after arrival at the site, it was determined that the elevation at the toe where the geophysical surveys would be performed is $806 \mathrm{ft}$ $(245.7 \mathrm{~m})$, which is $21 \mathrm{ft}(6.4 \mathrm{~m})$ above the top of the drainage blanket. Surveys with these sensors were still performed, although imaging of the drainage blanket with them was unlikely.

PHREATIC SURFACE MODELING RESULTS: As mentioned earlier, the phreatic surface was modeled assuming unclogged and clogged conditions of the filter material at conservation pool levels. The permeability values for no clogging, partial clogging, and fully clogged conditions are $\kappa=10^{-3} \mathrm{ft} / \mathrm{sec}, 10^{-5} \mathrm{ft} / \mathrm{sec}$, and $10^{-6} \mathrm{ft} / \mathrm{sec}$, respectively. Plots of the model results are shown in Figure 2. As expected, the elevation at which the phreatic surface intercepts the core rises as the pool level rises and the degree of clogging increases. When there is no clogging of the filter material (top plot, Figure 2), the phreatic surface passes through the core and intercepts the base of the drainage blanket on the downstream side of the dam. However, as the filter material begins to clog, the phreatic surface rises and intercepts the chimney drain at an elevation above the drainage blanket (center and bottom plots, Figure 2). As suggested in Figure 2, when the filter 
material is partially clogged there is a minimal rise in the phreatic surface; thus, the filter still performs well under these conditions. Even when the filter material is assumed fully clogged for the modeled parameters, the filter adequately manages the excess drainage. The model indicates that the water level within the chimney drain rises approximately $40 \mathrm{ft}(12 \mathrm{~m})$ at conservation pool level. This modeling exercise emphasizes the need for a geophysical technique that is capable of detecting the phreatic surface to depths up to $150 \mathrm{ft}$ (46 m).

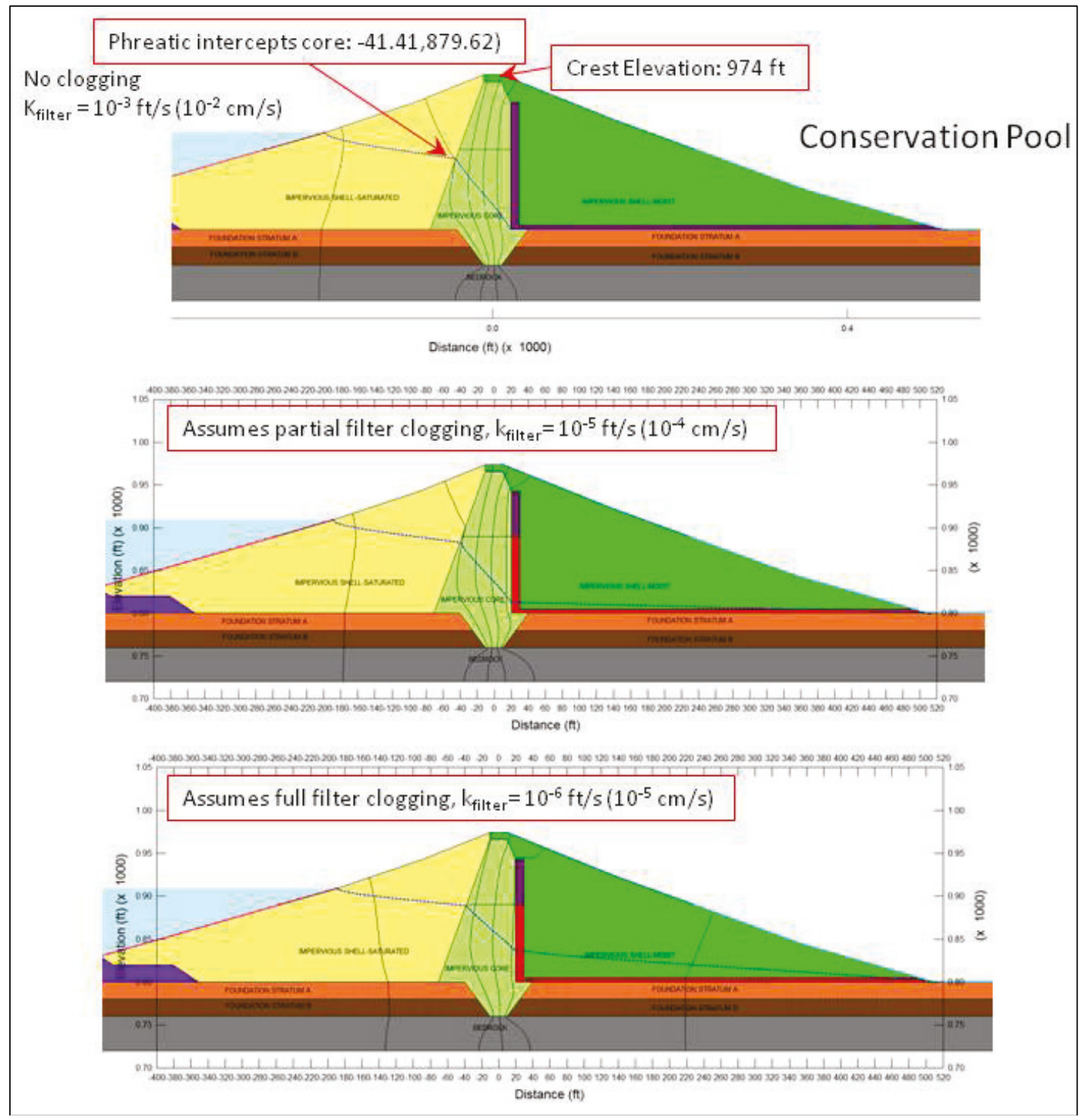

Figure 2. Model results showing the phreatic surface level for unclogged, partially clogged, and clogged filter material conditions at conservation pool conditions.

SITE DESCRIPTION: The general geographical coordinates for Canyon Dam are $29.881462^{\circ},-98.26746^{\circ}$. Measurements were acquired along three survey lines located on the downstream embankment, i.e., one at the toe, one midway up the embankment, and one near the crest (Figure 3). All lines paralleled the crest of the dam, with station 0 aligned with survey pin station $70+00$. The crest survey line was positioned $25 \mathrm{ft}(7.6 \mathrm{~m})$ east of the dam centerline, which approximates the center of the chimney drain. Table 1 provides the location of station 0 on each 
line and the length of each line. The line length varied depending on the electrode spacing used for the electrical resistivity surveys. Figure 4 shows the view looking north along each survey line. Cultural features proximal to the survey lines that influenced the data include a telephone pole guide wire on the toe line and drop inlet on the mid line.

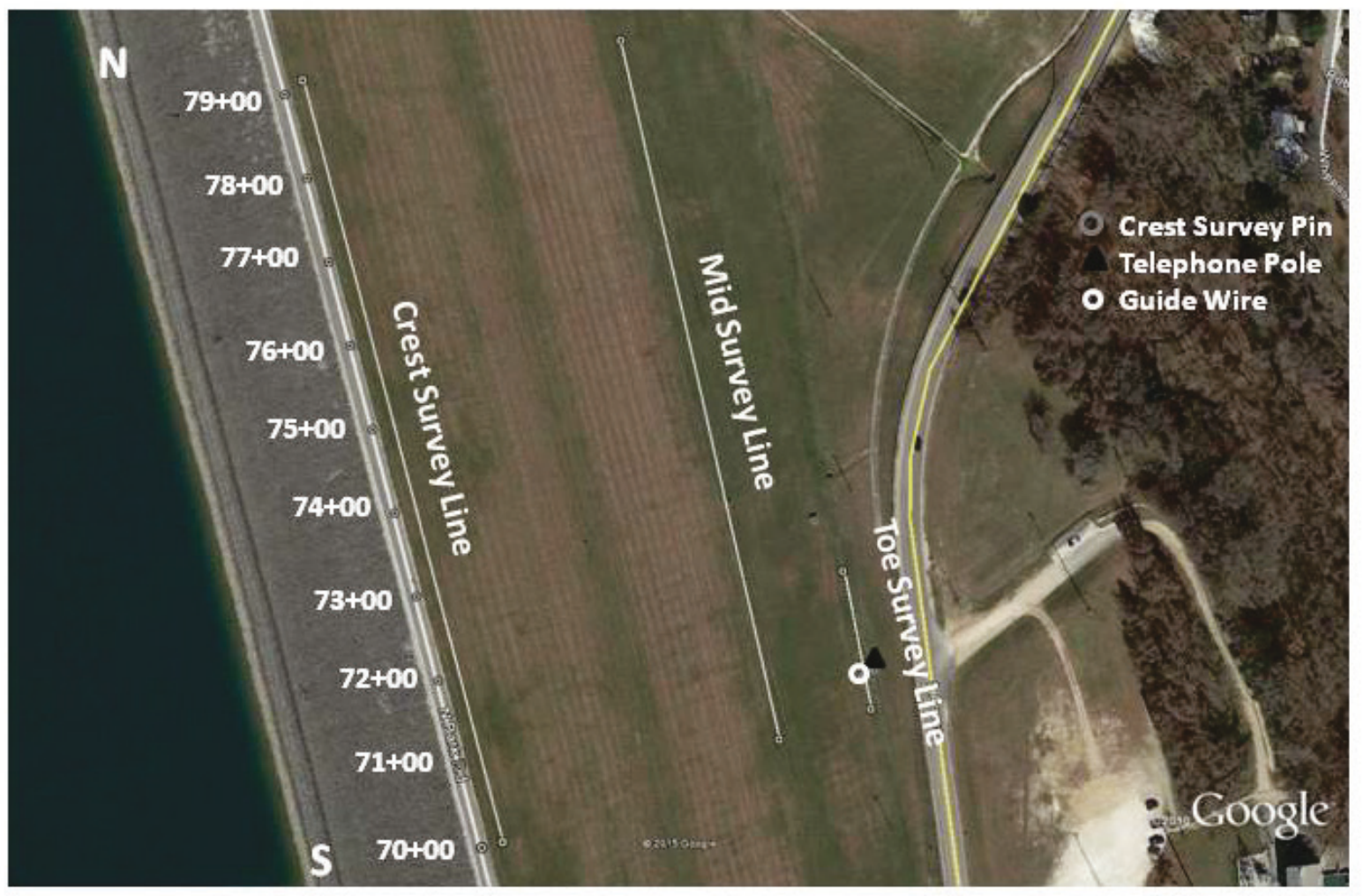

Figure 3. Location of three geophysical survey lines along the downstream embankment. Station 0 of each line aligns with survey pin location $70+00$. Google image accessed September 8, 2015.

Table 1. Coordinates of station 0 for each survey line.

\begin{tabular}{|l||l|l||l||c||}
\hline \hline Survey Line & Easting (m) & Northing $(\mathbf{m})$ & Elevation $\mathbf{( m / f t )}$ & Length $(\mathbf{m} / \mathbf{f t})$ \\
\hline Crest & 577452.31 & 3304742.40 & $295.805 / 970.4859$ & $277.5 / 910.43$ \\
\hline Mid & 577548.70 & 3304769.67 & $255.913 / 839.607$ & $277.5 / 910.43$ \\
\hline Toe & 577589.01 & 330477948 & $245.615 / 805.8211$ & $55.5 / 182$ \\
\hline
\end{tabular}




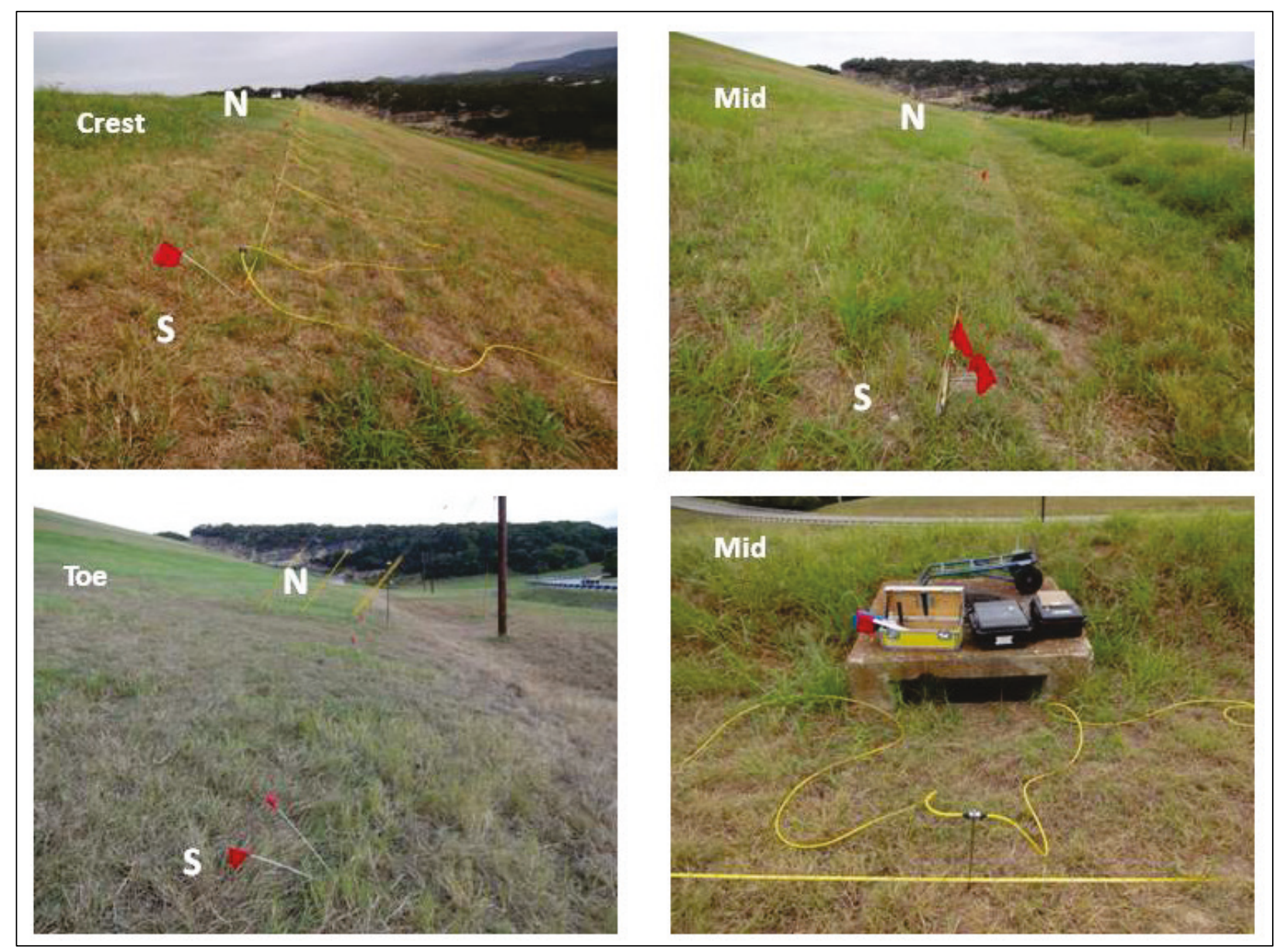

Figure 4. View looking north along each survey line. Note the telephone pole guide wire adjacent to the toe line (bottom left) and drop inlet proximal to the mid line (bottom right).

\section{DATA ACQUISITION AND PROCESSING}

Electrical resistivity. Electrical resistivity is a measure of how well a material resists the flow of current. For earthen materials, resistivity is dependent on moisture content, soil/rock type, water salinity, and temperature. In general, as moisture content, water salinity, and temperature increase, the electrical resistivity decreases. The addition of clay to a soil usually decreases the soil resistivity because of a clay's ability to absorb water. Rocks are generally more resistive than soils. An electrical resistivity survey involves hammering a line of metal stakes (electrodes) several inches into the ground and connecting them with wires to allow injection of a current into the ground through two electrodes and measuring the potential difference between two different electrodes. The potential difference is converted to apparent resistivity (units of ohm-m) using a geometry factor calculated from the current and potential electrode separations. The type of electrode array used determines the selection of which current and potential electrodes will be used during a measurement. A dipole-dipole array was used in this investigation. This array uses the same electrode spacing (a) between the two current electrodes and two potential electrodes and increases the distance (na) between the two pairs of electrodes by multiples (n) of "a" (Figure 5a). At large $\mathrm{n}$ (about 8), the potential difference generally becomes too small to measure, so the current and potential electrode pairs are shifted one electrode and the process repeated. In this manner, it 
is possible to obtain a 2-D image of the subsurface. The dots in Figure $5 \mathrm{~b}$ represent pseudo-depth locations of resistivity measurements for given electrode spacings. Modern ER systems allow initial placement of electrodes and electrode cables and use automatic switching capabilities to measure the multiple electrode combinations. An Advanced Geosciences Inc. (AGI) SuperSting ${ }^{\mathrm{TM}}$ R8 earth resistivity system with electrode switch box (Figure 6) was used to acquire the resistivity data. This is an eight-channel system, meaning eight readings, i.e., electrode pairs, are acquired during one measurement. An initial layout of 84 electrodes was used with 6 cables of 14 electrode take-outs. The line length was extended to 112 electrodes by employing two roll-along sequences of one cable (14 electrodes). The electrode spacing, "a," controls the depth of investigation, with a greater electrode separation providing a greater depth of investigation. An electrode spacing of $8.2 \mathrm{ft}(2.5 \mathrm{~m})$ was used for the crest and mid-survey lines, giving a total line length of $910.4 \mathrm{ft}$ $(277.5 \mathrm{~m})$. The survey line at the toe had a $1.64 \mathrm{ft}(0.5 \mathrm{~m})$ electrode spacing, giving a total line length of $182.1 \mathrm{ft}(55.5 \mathrm{~m})$.

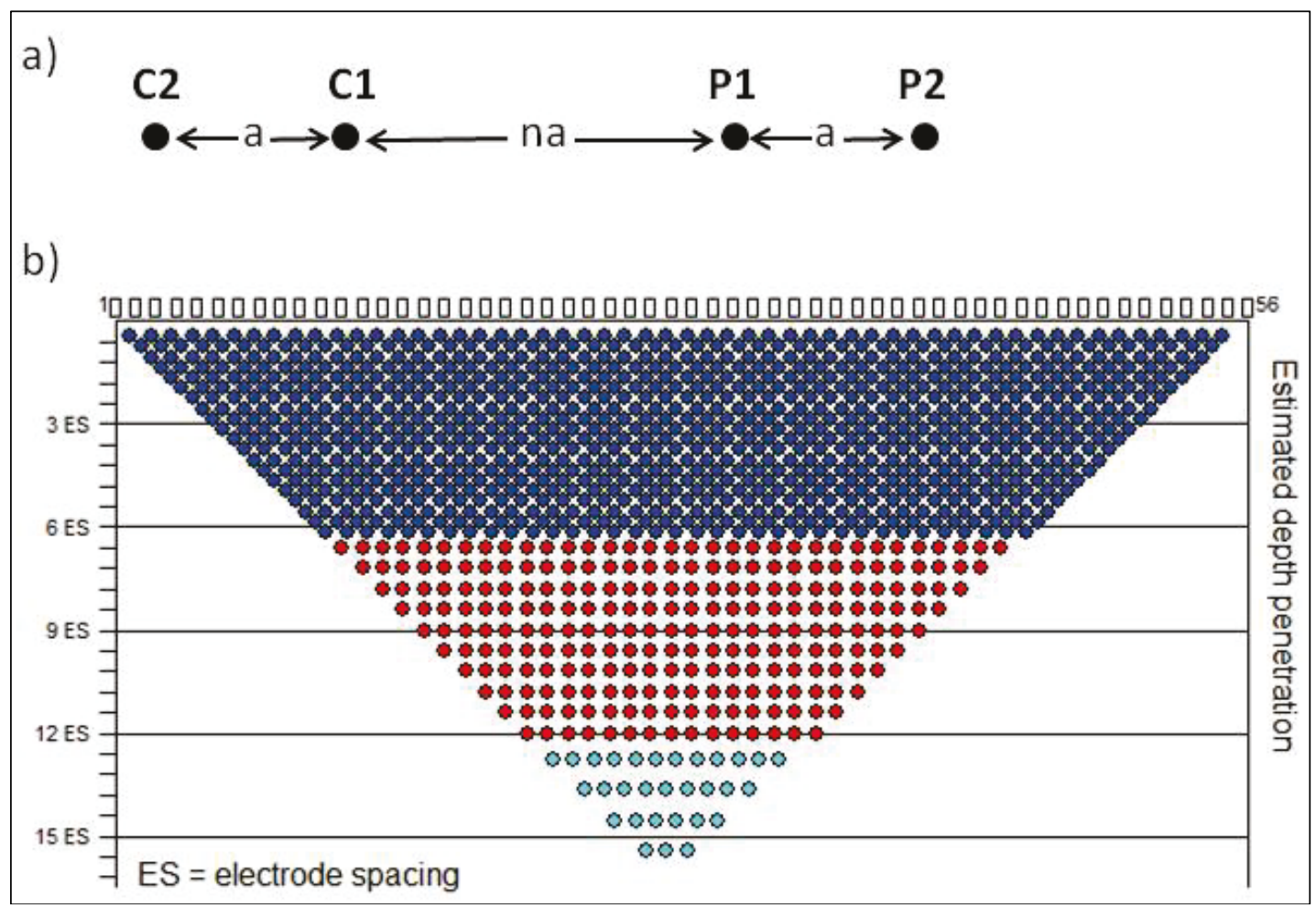

Figure 5. Dipole-dipole electrical resistivity configuration (a). By using different values for "a" and "n," 2-D coverage of the subsurface is obtained (b). In (b), the rectangles along the surface represent electrodes (in this example 56), and the dots in the subsurface represent the pseudo location of a measurement. For a given number of electrodes, as the electrode spacing increases, the number of measurements at depth decreases. 

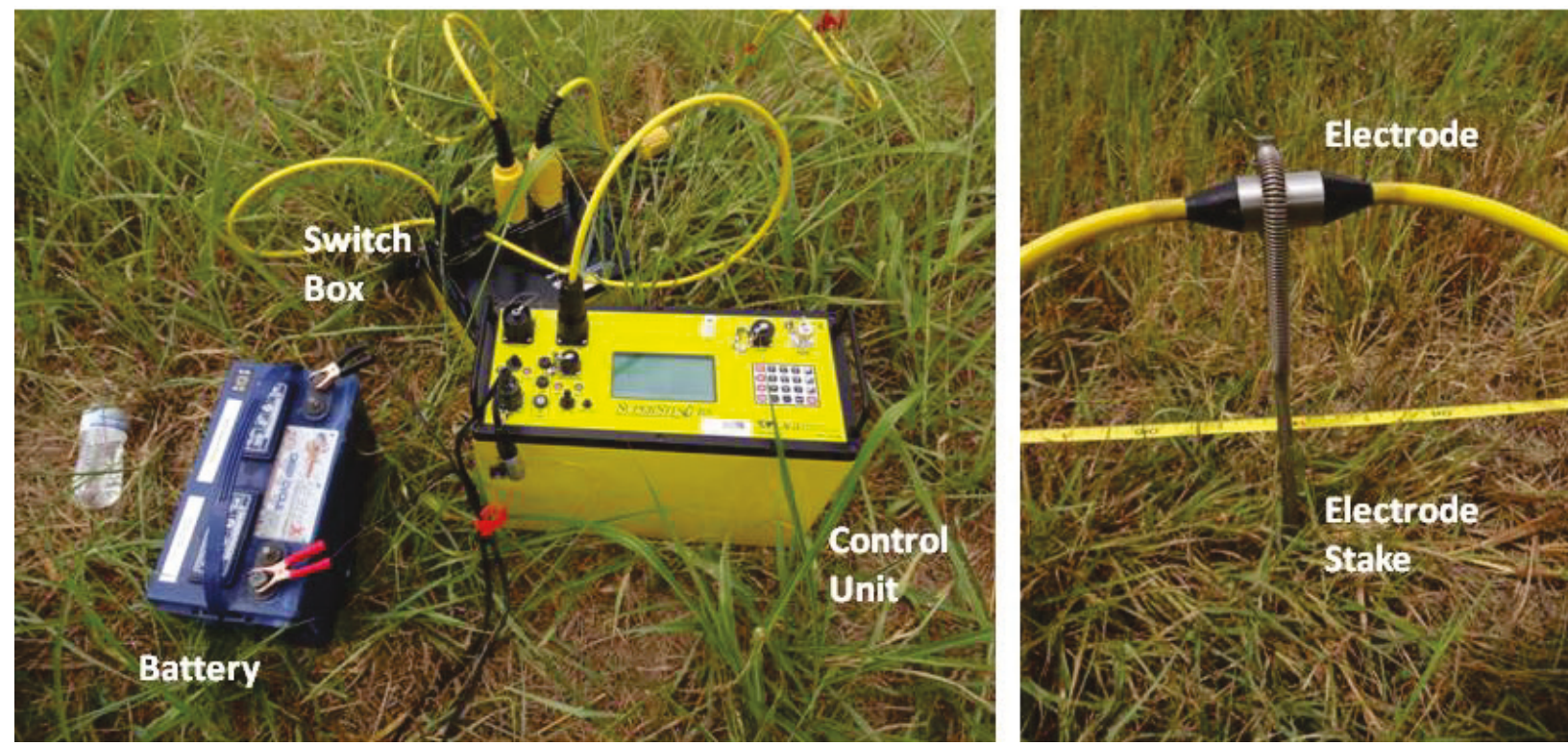

Figure 6. Advanced GeoSciences Inc. SuperSting ${ }^{\mathrm{TM}}$ R8 system used to acquire the electrical resistivity data.

The data were processed using the AGI EarthImager 2-D resistivity inversion software. Standard resistivity inversion procedures, e.g., removal of noisy data and negative resistivities, were followed. Because the results are influenced by variations in electrode elevation, the elevations of some, if not all, of the electrodes along a given resistivity line were included in the inversion process. The inversion results are presented as 2-D color plots of apparent resistivity with depth. The "hotter" colors (reds, pinks) represent higher values, whereas the "colder" colors (blues) indicate lower values.

Electromagnetic (EM) induction. The Geonics EM31 and EM38-MK2 are frequency-domain EM induction sensors (Figure 7) that measure apparent terrain conductivity and can also detect metallic objects. The conductivity of a material is dependent on the degree of water saturation, types of ions in solution, porosity, chemical constituents of the soil, and the physical nature of the soil. Because of these factors, conductivity values can range over several orders of magnitude. The EM system consists of a transmitter and receiver coil separated by a fixed distance. An alternating current, commonly in the 1 to 20 kilohertz range, is passed through the transmitter coil, thus generating a primary time varying magnetic field. This primary field induces eddy currents in the subsurface conductive materials (where the common phrase EM induction is derived). These eddy currents are the source of a secondary magnetic field that is detected by the receiver coil along with the primary field. Under a fairly wide range of conditions, the measured component that is 90 degrees out of phase (quadrature component) with the primary field is linearly related to the terrain conductivity. Conductivity is measured in units of millisiemen per meter $(\mathrm{mS} / \mathrm{m})$. 


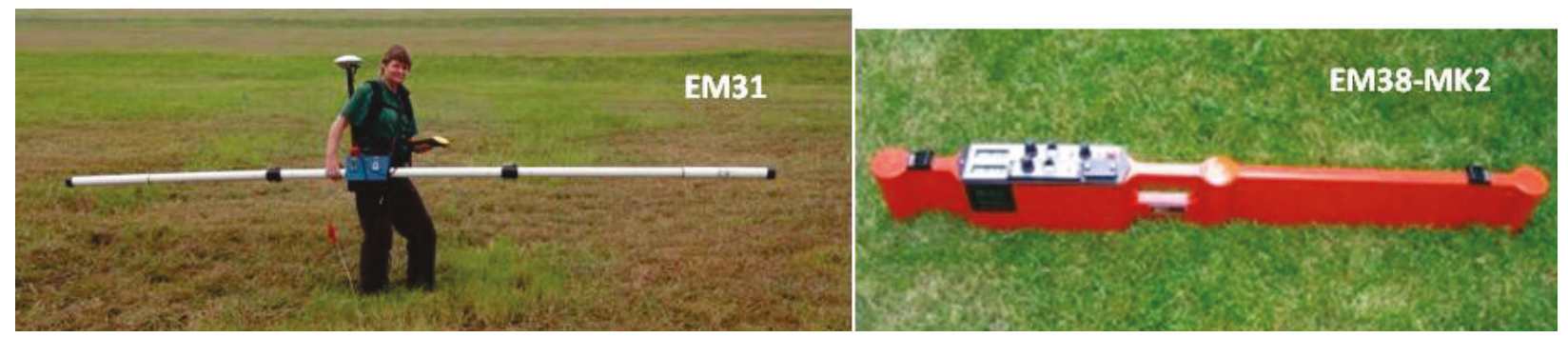

Figure 7. Geonics EM31 (left) and EM38-MK2 (right) electromagnetic induction instruments.

There are two components of the induced magnetic field measured by the EM equipment. The first is the quadrature phase component, sometimes referred to as the out-of-phase or imaginary component, which gives the ground conductivity measurement. In addition to soil moisture variations, disturbances in the subsurface caused by compaction, soil removal and fill activities, or buried objects can produce conductivity readings different from that of the background values, thus indicating anomalous areas. Electrical conductivity is a positive valued parameter; however, because of the design of the instrument, it is possible to obtain a negative value when the instrument passes over a metallic object. Although a negative conductivity value is physically meaningless, it does aid in the detection of metallic material. The second component is the in-phase or real component, which is the ratio of the induced secondary magnetic field to the primary magnetic field. The in-phase component is primarily used for calibration purposes; however, it is also significantly sensitive to metallic objects and, therefore, very useful when looking for buried metal. The in-phase component is measured relative to an arbitrarily set level and assigned units of parts per thousand (ppt). Because it has an arbitrary reference level, the reading can be either a positive or negative value.

The EM31 operates at a frequency of $9.8 \mathrm{kHz}$. It has a transmitter-receiver coil separation of $12 \mathrm{ft}$ $(3.7 \mathrm{~m})$ and an effective depth of investigation of approximately $20 \mathrm{ft}(6.1 \mathrm{~m})$ when operated in the vertical dipole orientation. The EM38-MK2 operates at $14.6 \mathrm{kHz}$. It has two receiver coils separated by $3.28 \mathrm{ft}(1 \mathrm{~m})$ and $1.64 \mathrm{ft}(0.5 \mathrm{~m})$ from the transmitter coil, providing data from effective depth ranges of $4.9 \mathrm{ft}(1.5 \mathrm{~m})$ and $2.5 \mathrm{ft}(0.75 \mathrm{~m})$, respectively, when operated in the vertical dipole orientation. For both instruments, data were collected at 0.2 -sec intervals along the toe survey line and stored in a data logger for later download. The data were processed using Geonics DAT31/DAT38-MK2 software and plotted as a 1-D profile.

Ground Penetrating Radar (GPR). The GPR data were acquired using a Sensors \& Software (S\&S) pulseEKKO PRO with a 200-MHz antenna. Other antenna frequencies $(100 \mathrm{MHz}, 50 \mathrm{MHz})$ were also used; however, the data were lower resolution and did not provide additional information; therefore, these data are not presented. The antenna was mounted on a cart and pushed along the survey line at a slow walking pace (Figure 8). The data were collected at 3.94-in. (10-cm) intervals along the survey line and viewed and stored on a digital video logger (DVL). The data were post-processed using S\&S EKKO_Project 3 software. Basic processing steps included dewow (or signal saturation correction) to remove the low frequency component induced by the transmit signal, an average background subtraction to enhance dipping events, such as hyperbolas from point targets, and a spreading and exponential compensation (SEC) gain to enhance the data. The SEC gain compensates for the spherical spreading losses and exponential ohmic dissipation of energy. The data were then plotted as a gray-scale 2-D profile for interpretation. The depth of investigation achieved was about $4.9 \mathrm{ft}(1.5 \mathrm{~m})$. 


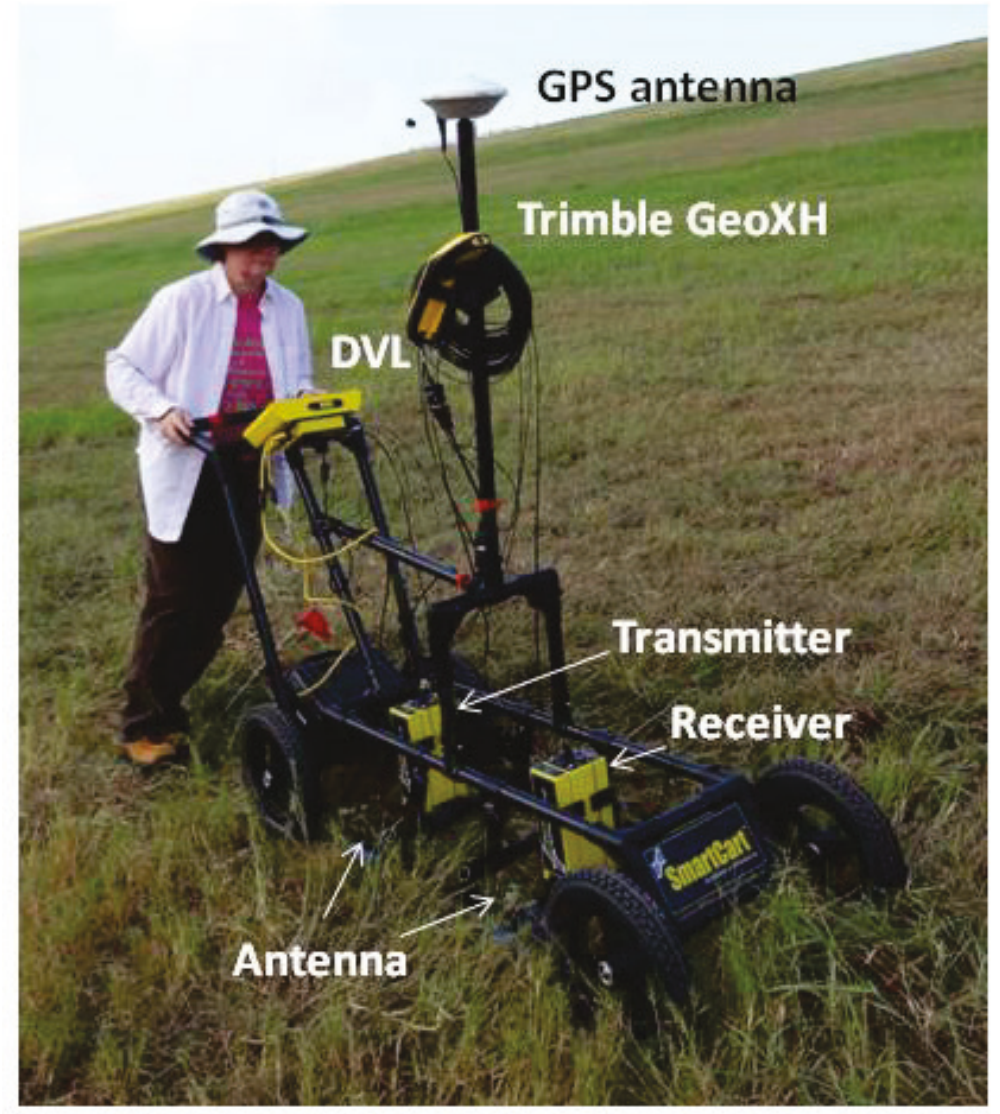

Figure 8. Sensors and Software pulseEKKO PRO GPR system with $200 \mathrm{MHz}$ antenna.

Global Positioning System (GPS). A Trimble GeoXH global positioning system (GPS) was used to collocate the data during acquisition (Figure 9). It was also used to acquire the survey line locations and other features of interest. The GeoXH combines a global (GNSS) receiver with a field computer. It can provide decimeter accuracy after post-processing. In the field, positions were measured within $1.64 \mathrm{ft}(0.5 \mathrm{~m})$. Positional data pertaining to the electrical resistivity electrode positions, survey line end points, and general features were post-processed; location data collected while acquiring data were not post-processed.

RESULTS: The inversion results of the electrical resistivity data for the crest, mid, and toe survey lines are presented in Figure 10. In each plot, the horizontal axis is distance (in feet) along the survey line from south to north. The vertical axis is elevation (in feet) and differs depending on line location. Also, the depth of investigation for the crest and mid sections is greater than the toe section because of the difference in electrode spacing used. The color bar represents apparent electrical resistivity in ohm-m; note that the scales differ for each plot. Table 2 provides information on dam metrics relevant to the discussion that follows. 


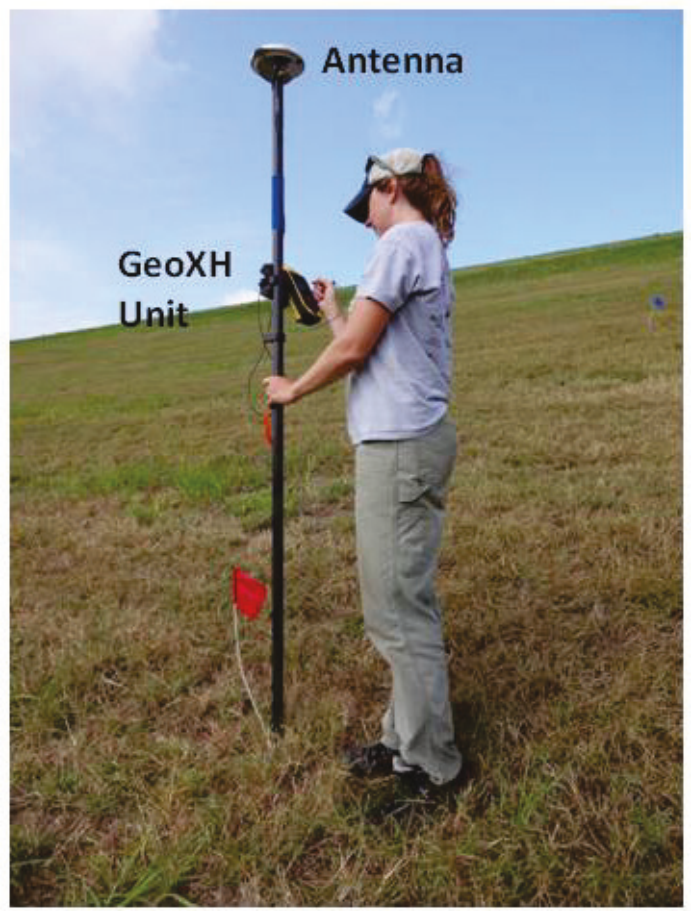

Figure 9. Trimble GeoXH GPS unit used for positioning data.

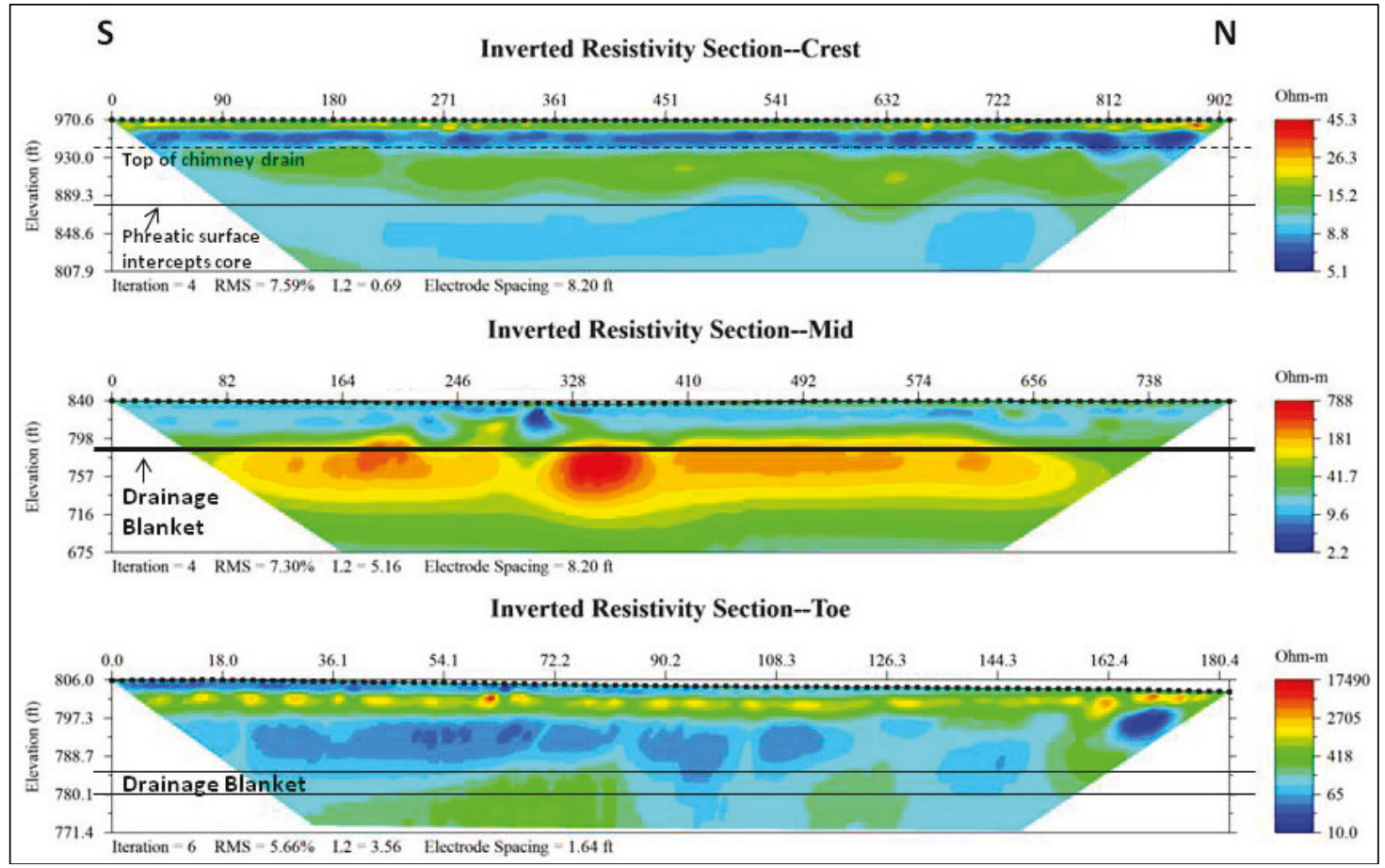

Figure 10. Results of the inverted electrical resistivity data for the crest (top), mid (middle), and toe (bottom) survey lines. The horizontal axis represents distance (in feet) along the survey line from south to north. Station 0 of each line aligns with station $70+00$ on the crest. 


\section{Table 2. Relevant dam information.}

\begin{tabular}{|l||l||}
\hline \hline Feature & Elevation (ft/m) \\
\hline \hline Top of dam & $976.5 / 297.6$ \\
\hline Top of chimney drain & $943.0 / 287.4$ \\
\hline Top of drainage blanket & $785.0 / 239.3$ \\
\hline Bottom of drainage blanket & $780.0 / 237.7$ \\
\hline Conservation pool phreatic intercepts core & $879.3 / 268.0$ \\
\hline
\end{tabular}

Crest line. The resistivity survey performed over the chimney drain (crest) achieved a depth of investigation of approximately $163 \mathrm{ft}(50 \mathrm{~m})$, thus extending to an elevation of $808 \mathrm{ft}(246 \mathrm{~m})$, which is $23 \mathrm{ft}(7 \mathrm{~m})$ above the top of the drainage blanket. The inverted resistivity section (Figure 10 top plot) shows that the majority of the volume imaged has an apparent resistivity less than $20 \mathrm{ohm}-\mathrm{m}$, suggesting a moist material. This is unexpected because the filter material is a dry crushed limestone (USCS classification GW), and a typical resistivity value would be greater than $90 \mathrm{ohm}-\mathrm{m}$. A low-resistivity layer (less than $10 \mathrm{ohm}-\mathrm{m}$ ) is present between elevations 960 and $940 \mathrm{ft}$. This layer is comprised of the clayey embankment fill material that overlays the top of the chimney drain, which is at elevation $943 \mathrm{ft}$. It likely has a high moisture content (possibly wet). Within the chimney drain, below an elevation of about $889 \mathrm{ft}(271 \mathrm{~m})$, the apparent resistivity is 8 to $10 \mathrm{ohm}-\mathrm{m}$, which also suggests a high-moisture-content material. The inversion results indicate a possible drainage path at the south end of the survey line between the upper and lower low-resistivity regions. It is interesting to note that the elevation of the deeper low-resistivity area approximates that of the $879 \mathrm{ft}(268 \mathrm{~m})$ determined in the conservation pool modeling where the phreatic surface intercepts the core. This is probably just a coincidence, because the conservation pool model (Figure 2a top plot) shows that the phreatic surface intercepts the core and deflects downward toward the drainage blanket.

Mid line. The mid resistivity survey used the same electrode spacing as the crest and achieved a similar depth of investigation $(165 \mathrm{ft} / 50 \mathrm{~m})$. The inverted resistivity section is the center plot in Figure 10. This line is shorter than the crest line because of an error when moving the last set of electrodes. Relative to the crest line, the bottom $32 \mathrm{ft}(9.8 \mathrm{~m})$ of it corresponds to the upper $32 \mathrm{ft}$ of the mid line. Within this depth range, there is agreement between the two sections, i.e., both sections exhibit low resistivity values $(<20 \mathrm{ohm}-\mathrm{m})$. However, because the embankment fill is a clay material, these values are typical for moist clay. The low resistivity anomaly (dark blue circular shape) beneath station 303.4 is caused by a corrugated metal pipe in a drop inlet (pictured in Figure 4). Between the low resistivity layer and drainage blanket (denoted by a heavy black line), there is a moderately resistive (20 to $100 \mathrm{ohm}-\mathrm{m}$ ) material (green, elevation 805 to $785 \mathrm{ft}$ ). This resistivity range likely corresponds to the drier clayey material within the embankment. Beneath the drainage blanket is a high resistivity $(>100 \mathrm{ohm} \mathrm{m})$ layer that is likely associated with limestone; this layer extends to about elevation $736 \mathrm{ft}$. The moderate resistivity material below could be associated with a shale.

Toe line. The inverted resistivity results for the toe line are shown in the bottom plot of Figure 10. Prior to discussing this line, note that the color shading in this plot cannot be directly compared to the color scheme in the crest or mid plots. The resistivity range of the toe section is much greater than that of the other two sections. Use of a smaller electrode spacing $(1.64 \mathrm{ft} / 0.5 \mathrm{~m})$ allowed 
imaging of the drainage blanket and below. The upper $2 \mathrm{ft}(0.6 \mathrm{~m})$ of material on the south end (station 0-100) has a lower resistivity than the northern end. Below this depth the resistivity is higher, and there is a thin, very high resistivity $(>1,000 \mathrm{ohm}-\mathrm{m})$ layer at approximate elevation 801. Between elevations 797 to $785 \mathrm{ft}$ (top of the drainage blanket), the resistivity is lower, but still moderate to high. On the north end of the section, centered beneath station 169, is a low resistivity anomaly, suggesting a moist material. The location of the drainage blanket is marked by two black lines. The drainage blanket exhibits moderate to high resistivity values, which is expected for a dry, crushed limestone. The material below the drainage blanket has similar resistivity values.

The EM31 and EM38-MK2 data acquired along the toe survey line are shown in Figure 11. The spike in the in-phase (IP) and conductivity curves in the EM38 data (top plot) at the north end is probably caused by a small, shallow metallic object. The spike in the conductivity curve at $x=3304809$ is probably caused by a shallow, geologic feature, e.g., rock, because there is no similar response in the in-phase curve. The low conductivities in both the EM38 and EM31 (bottom plot) correspond to the moderate resistivity values discussed above.

Figure 12 shows the profile of the GPR data acquired along the toe survey line. The horizontal axis represents distance (in feet) along the survey line; the right vertical axis is two-way signal propagation time (in nanoseconds, ns); and the left vertical axis is depth (in feet) assuming an electromagnetic wave velocity of $0.328 \mathrm{ft} / \mathrm{ns}(0.1 \mathrm{~m} / \mathrm{ns})$. Depth of investigation with the $200 \mathrm{MHz}$ antenna was about $8 \mathrm{ft}(2.4 \mathrm{~m})$. Because of the high signal attenuation of the subsurface material, the lower frequency antennas used were unable to achieve a deeper depth of investigation; therefore, those data are not presented. The GPR was unable to image the drainage blanket, which is $21 \mathrm{ft}(6.4 \mathrm{~m})$ below ground surface at this location. The large, hyperbolic feature in the data seen at station 40 is a reflection from a surface feature (tie-down cable for a telephone pole). The other prominent feature in the data is the southward-dipping reflector in the northern end of the profile. A polarity reversal of the signal has occurred (white-black-white pattern), which can happen when a dry material overlays a moister material. This reflector could be associated with the low resistivity anomaly observed at the northern end of the apparent resistivity data. 


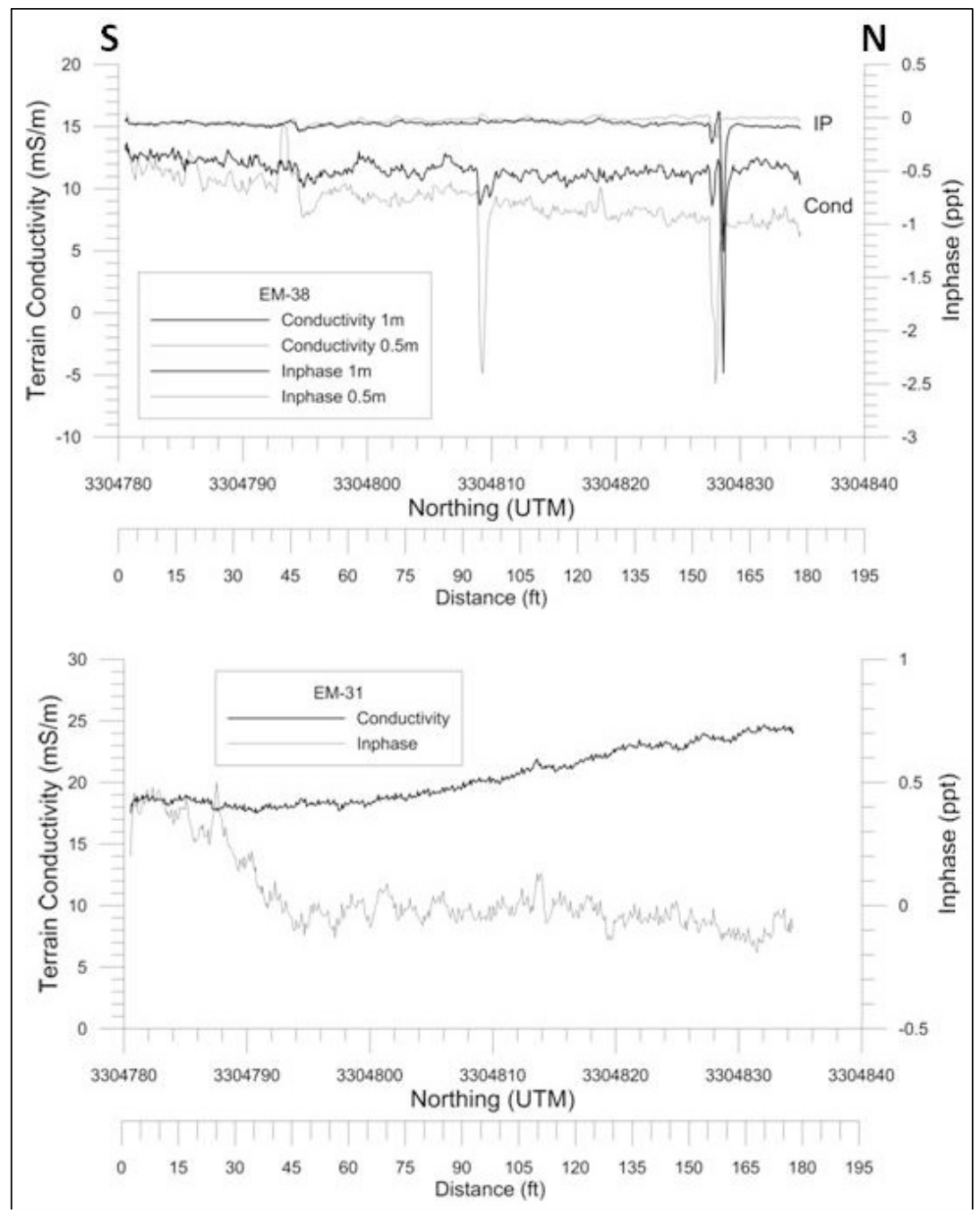

Figure 11. EM31 (bottom) and EM38-MK2 (top) data plots acquired along the toe survey line. The survey line runs south to north.

SUMMARY: A geophysical study was conducted at Canyon Dam in Comal County, Canyon Lake, TX, to determine the feasibility of using geophysical methods for detecting/identifying areas that may be clogged within the chimney drain and/or drainage blanket. The primary geophysical method used was electrical resistivity because it is capable of imaging to variable depths as required at different locations along the downstream embankment. Secondary methods, electromagnetic induction (shallow sounding sensors) and ground penetrating radar, were used along the embankment toe. These two methods did not provide any significant contribution to the study because they did not have the depth of investigation capability required to image the drainage blanket (21-ft $(6.4-\mathrm{m})$ depth at the toe survey location). Note that there are EM induction sensors that do have deep sounding capabilities. Three electrical resistivity surveys were conducted; one near the crest centered over the chimney drain, one at mid embankment, and the other at the toe. The resistivity surveys were able to image the embankment fill, drainage blanket, and deeper material. The survey performed near the crest did not image down to the drainage blanket; however, use of a longer electrode spacing would allow this. 


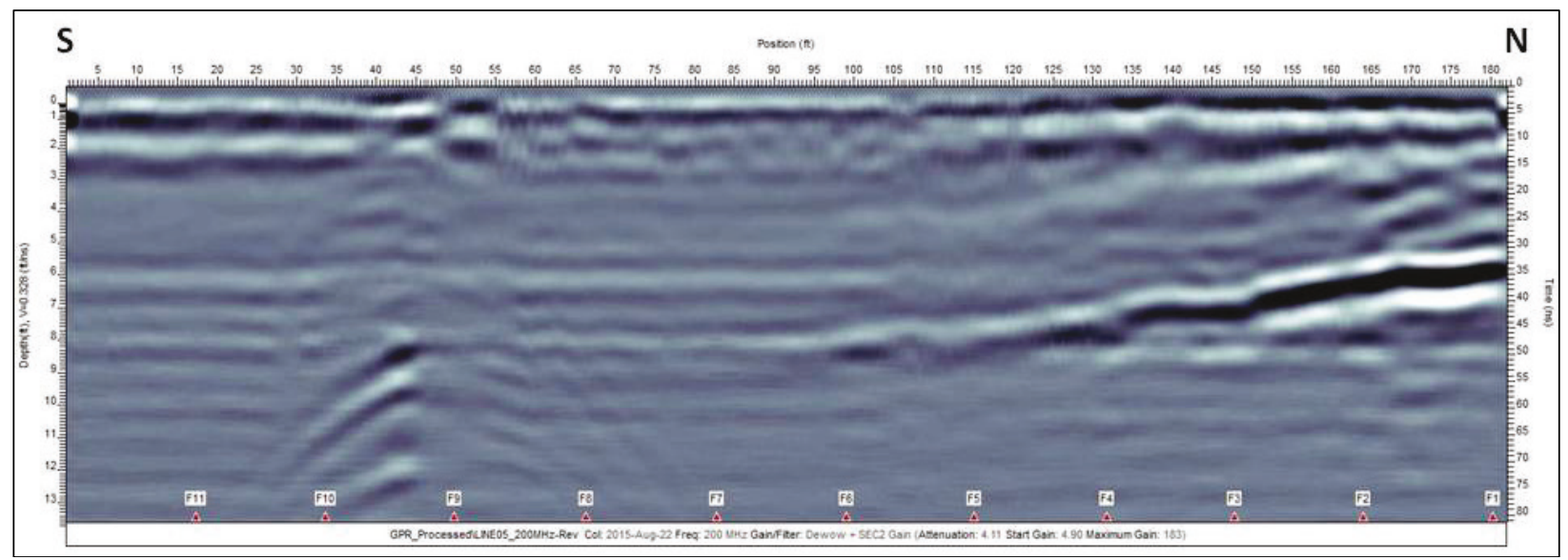

Figure 12. GPR profile acquired using a $200 \mathrm{MHz}$ antenna along the toe survey line.

The resistivity inversion results for the survey performed over the chimney drain reveal that the filter material in the drain has resistivity values significantly lower than what was expected for a dry crushed limestone, and that the material may range from moist to wet. There is an approximately 2-ft (6-m) thick layer (elev. 960 to $940 \mathrm{ft}$ ) directly above the top of the chimney drain (elev. $943 \mathrm{ft}$ ) that has a relatively high moisture content. This layer likely consists of the clayey embankment fill. It is possible that this layer may drain into a region within the chimney drain, at elevation $889 \mathrm{ft}$. This deeper, high-moisture-content region extends to at least elevation $808 \mathrm{ft}$ (maximum depth imaged at this location).

The resistivity survey performed at mid embankment did not find any anomalous conditions that would suggest excess moisture in this area. One isolated location at the north end of the toe survey line (approximate elevation $797 \mathrm{ft}$ ) may have high moisture conditions. The GPR imaged a dipping layer at the same location.

This feasibility study has shown that the use of geophysics is beneficial for determining the general state, i.e., clogged or unclogged, of the chimney drain and drainage blanket. It provides an approach to interrogate the internal condition of the dam and identify potential problems before they manifest on the surface. Of the locations surveyed, the apparent resistivity sections along the mid and toe lines are representative of conditions for an unclogged drainage blanket. The electrical resistivity survey conducted over the chimney drain suggests that both the clay material directly overlaying the chimney drain and crushed limestone material that comprises the chimney drain have a high moisture content. These results may indicate some level of clogging within the chimney drain. It would be beneficial to conduct additional geophysical surveys over the chimney drain along the length of the dam to determine if similar conditions exist. Acquiring data further down the embankment would also be useful in determining if there is seepage from the chimney drain into the embankment.

Although the electrical resistivity method was successful in determining the state of the filter material, it is a relatively slow and laborious technique. Other geophysical techniques that could be applied in the future include capacitively coupled electrical resistivity and deep sounding EM induction. Both methods can be towed behind an ATV, although the steep sides of the embankment do provide a challenge to prevent the sensor from rolling. 


\section{REFERENCE}

U.S. Army Corps of Engineers. 2014. Semi-Quantitative Risk Assessment (SQRA). Canyon Dam (TX00004), Guadalupe River, Texas, Embankment and Spillway. USACE: Fort Worth District, Southwest Division. 